\title{
PlioMIP2 simulations using the MIROC4m climate model
}

Wing-Le Chan ${ }^{1}$, Ayako Abe-Ouchi ${ }^{1,2}$

${ }^{1}$ Atmosphere and Ocean Research Institute, The University of Tokyo, Kashiwa, 277-8564, Japan

${ }^{2}$ National Institute for Polar Research, Tachikawa, 190-8518, Japan

5 Correspondence to: Wing-Le Chan (wlchan@aori.u-tokyo.ac.jp)

Supplementary figures

Model SST anomaly minus PRISM3 proxy SST anomaly $\left({ }^{\circ} \mathrm{C}\right)$

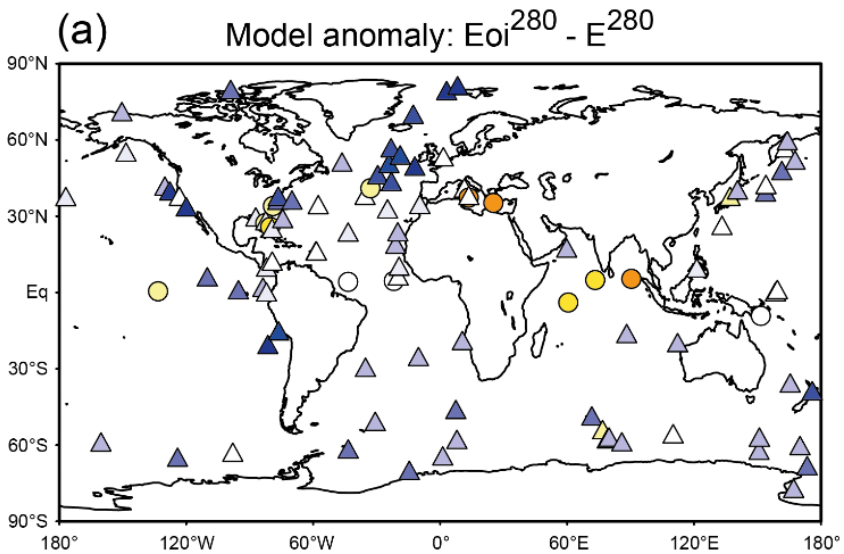

(b) Model anomaly: $\mathrm{Eoi}^{350}-\mathrm{E}^{280}$

(c) Model anomaly: $E i^{400}-E^{280}$

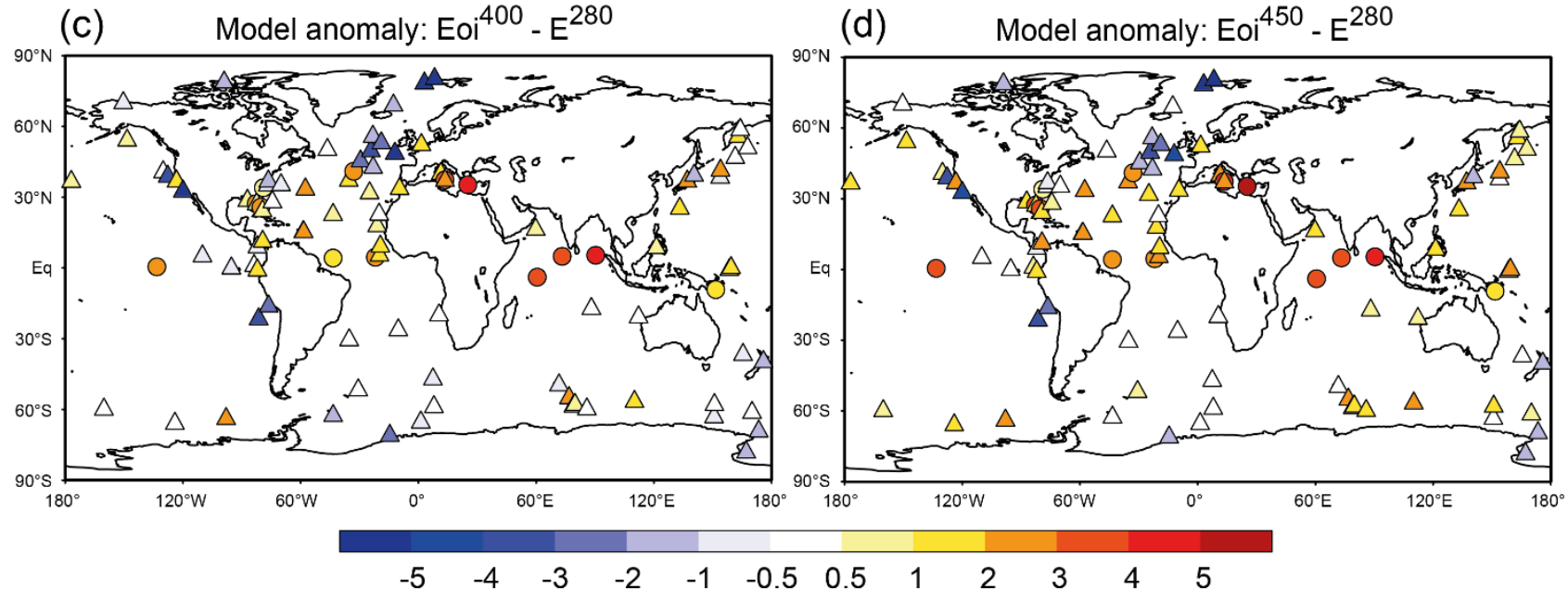

PRISM3: $\triangle$ Pliocene warmer $\bigcirc$ Pliocene cooler

10 Figure S1: As in Figure 15(a), but for the PlioMIP2 experiments with various $\mathrm{CO}_{2}$ levels. 
(a) Eoi ${ }^{400}$ SST anomaly minus PRISM4 SST anomaly $\left({ }^{\circ} \mathrm{C}\right)$

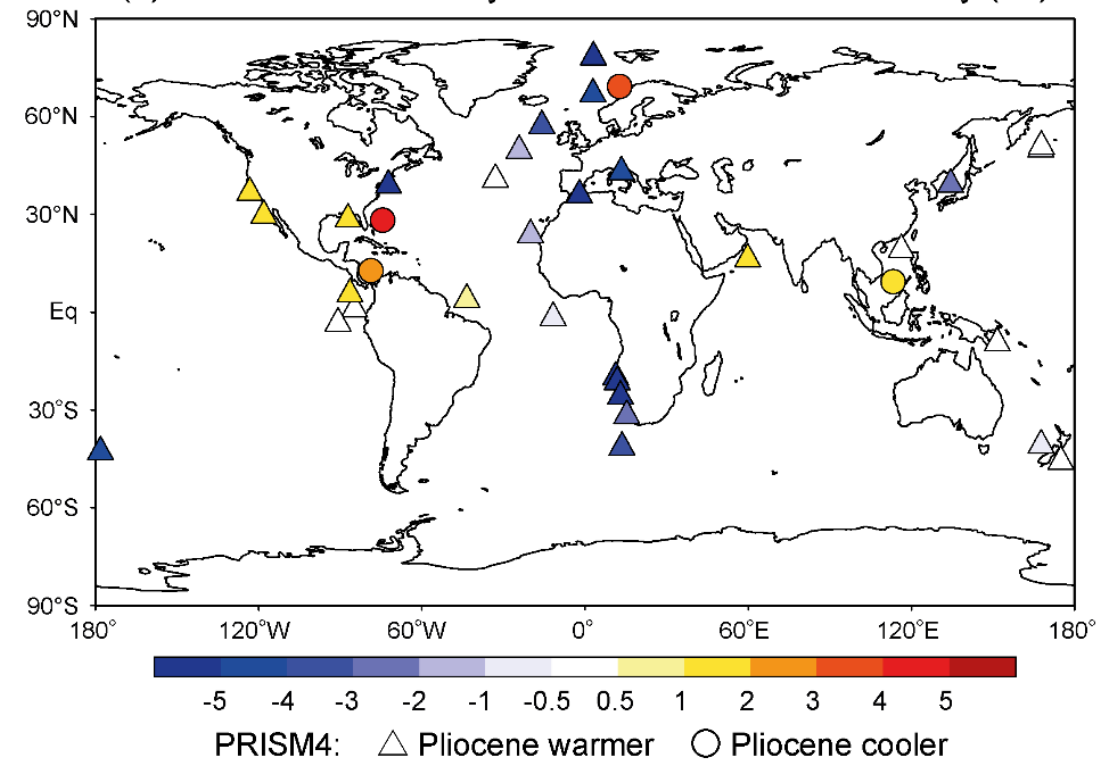

(b) Eoi ${ }^{400}$-Eplio1 SST anomaly $\left({ }^{\circ} \mathrm{C}\right)$ and comparison with PRISM4

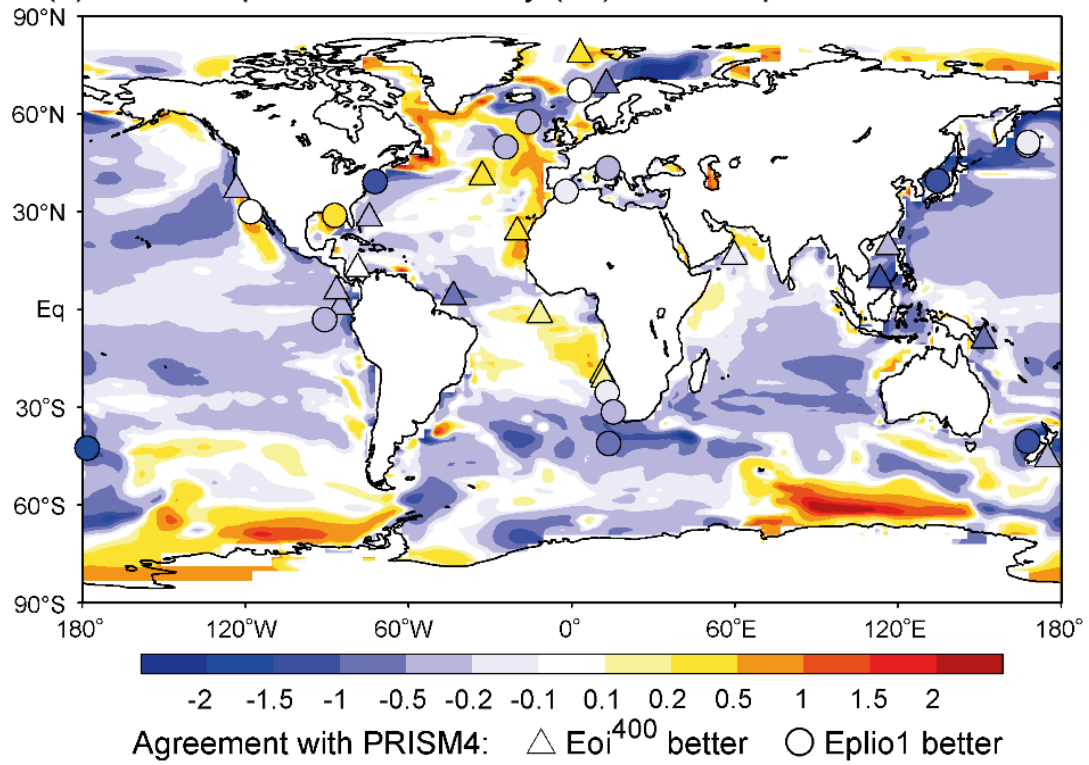

Figure S2: (a) Comparison of annual mean model SST anomalies and (PRISM4 - NOAA ERSSTv5) proxy data SST anomalies. Blue (red) indicates that model SST anomalies are smaller (greater) than those of proxy data. The shape of the symbols indicates whether proxy data suggests higher (triangle) SST in the Pliocene or lower (circle). (b) The difference between PlioMIP1 and

15 PlioMIP2 SST. The shape of the symbols at PRISM4 locations indicates whether PlioMIP2 agrees better with proxy data (triangle) or whether PlioMIP1 agrees better (circle). PRISM4 data used here refers to the broader 30ka interval data set. 